\title{
A Lei do Babaçu Livre: uma estratégia para a regulamentação e a proteção da atividade das quebradeiras de coco no Estado do Maranhão ${ }^{1}$
}

\section{The Law of Free Babaçu Coconut: a strategy for the protection and regulation of the activity of the coconut breakers, with a view to sustainable regional development in the State of Maranhão}

Miguel Etinger de Araújo Junior Universidade Estadual de Londrina, Londrina, PR, Brasil

Erika Juliana Dmitruk Universidade Estadual de Londrina, Londrina, PR, Brasil

João Carlos da Cunha Moura

Universidade Federal do Maranhão, São Luis, MA, Brasil

Resumo: Este trabalho realiza um resgate histórico da importância econômica do babaçu para a Região do Maranhão, investiga as razões do seu declínio e a atualidade dos conflitos decorrentes da sua extração e do seu beneficiamento. Discute a formação das quebradeiras de coco como grupo social e o movimento hoje encampado pela subsistência do seu modo de vida e de reprodução social. Analisa a continuidade da importância econômica do babaçu e a necessidade de leis de proteção à atividade de extração dessa palmeira, bem como leis que aproveitem a vocação local para a atividade econômica incluindo trabalhadores(as) rurais. Além disso, neste trabalho perquire-se a competência para a edição dessas leis e dos aspectos que devem ser regulados..

Palavras-chave: Direito Ambiental. Conhecimento tradicional. Quebradeiras de coco babaçu.
Abstract: This paper provides a historical review of the economic importance of babassu coconut for the region of Maranhão, the reasons for its decline and current conflicts arising from their extraction and processing. Investigates the formation of the coconut breakers as a social group and association embraced by today's subsistence way of life and social reproduction. Analyzes the continued economic importance of babassu coconut and the necessity for laws to protect extraction activity, as well as enjoy the local vocation for economic activity including rural workers. Inspect jurisdiction to issue these laws and aspects that should be regulated.

Keywords: Environmental Law. Traditional Knowledge. Babassu Coconut Breakers.

${ }^{1}$ Recebido em: 26/06/2013

Revisado em: 15/08/2013

Aprovado em: 1\%03/2014 


\section{Introdução}

O presente artigo tem por objetivo investigar em que medida existe a necessidade de edição de legislação protetiva e regulamentadora da atividade das quebradeiras de coco babaçu, a fim de fomentar o desenvolvimento regional, no Estado do Maranhão, de forma horizontalizada.

A problemática de pesquisa se revela importante, uma vez que a Região do Maranhão vem sendo assediada por inúmeros projetos industriais, de mineração e agronegócio, ficando as atividades regionais em segundo plano, rotuladas como atrasadas e subdesenvolvidas.

O trabalho busca dados que confirmem a necessidade de alternativas locais de desenvolvimento, que visem principalmente respeitar a vocação das populações tradicionais, sua qualidade de vida e a manutenção do valor cultural de suas atividades, dando principal ênfase às quebradeiras de coco babaçu.

Para isso, em um primeiro momento, será investigado o sistema produtivo agroextrativista do babaçu e sua viabilidade econômica, com a intenção de disponibilizar informações acerca dos processos de apropriação, pelos latifundiários e industriais - nacionais e estrangeiros - das riquezas geradas por essa economia. Apresenta-se, ainda, um quadro da atual conformação desta atividade econômica, conquistada pelas quebradeiras de coco em algumas cidades do Maranhão. Descreve-se o sistema das cooperativas e cantinas, em que o preço da amêndoa é mais justo e onde ainda ocorre a distribuição dos lucros (ou sobras) ao final de cada ano para todas as associadas.

Após, será reconstruído o processo de luta das quebradeiras de coco, desde o momento do acirramento dos conflitos (na década de 1970) até a construção de sua própria identidade.

Será apresentado um levantamento das principais dificuldades ainda vividas pelas quebradeiras de coco. Esse levantamento é feito a partir de pesquisas bibliográficas, sites das organizações formadas por essas mulheres e, também, por observação, entrevistas e pela participação destes pesquisadores no Encontro das Quebradeiras de Coco de Dom Pe- 
dro, São José dos Basílios e Governador Archer, Municípios no Estado do Maranhão, Brasil.

Por fim, a reflexão jurídica em torno do tema se propõe a trazer auxílios instrumentais buscados no ordenamento jurídico com o intuito de proteger e de valorizar a atividade das quebradeiras de coco.

\section{O Sistema Produtivo Agroextrativista e a Viabilidade Econô- mica do Babaçu}

Esta pesquisa foi iniciada perquirindo a trajetória da cultura do babaçu que está voltada para a própria subsistência da família do Período Colonial até a I Guerra Mundial, e que no decorrer da história vem a tornar-se a alternativa econômica mais imediata para o seu sustento. (AMARAL FILHO, 1980, p. 25)

Todavia, com o advento das guerras do século XX o fruto passou a ser cobiçado internacionalmente por suas propriedades (de limpeza, energética, cosmética) ${ }^{2}$. Depois da Primeira Guerra, ainda segundo Amaral Filho (1980, p. 25-26), a exploração do babaçu conheceu a fase do capital comercial. Para atender interesses predominantemente internacionais, muito é investido no Maranhão, e o babaçu passou a ser exportado.

Os proprietários de terras aproveitaram-se da força produtiva dos agricultores extrativistas, cobrando diversas rendas para autorizar que eles continuem suas atividades de cata do coco. Pode-se citar como exemplo: a renda fundiária, o foro, o arrendamento, bem como a meação do resultado da catação. (REIS, 2008, p. 28)

Para se instalarem na região, as indústrias internacionais receberam terras e incentivos do governo estadual. Nesse período abundava a edição de leis promovendo a colonização estrangeira no Maranhão. Mesmo assim, os agricultores extrativistas não sofrem uma real ameaça de desocupação, pois os fazendeiros ainda percebem sua dependência em relação à mão de obra coletora (REIS, 2008, p. 28), por isso, é possível afirmar

2 Valorizado nos dias atuais também por ser produto verde, advindo de atividades artesanais de agricultoras pobres da Amazônia. 
que a principal destinação do babaçu foi o mercado externo de amêndoa e óleo. A produção era exportada in natura para os Estados Unidos e Europa até os anos de 1950. (AYRES JÚNIOR, 2007, p. 47)

Segundo Mesquita (1999), o fluxo de comercialização do babaçu seguia o seguinte quadro (não alterado até o recrudescimento do movimento das quebradeiras de coco e ainda válido em algumas regiões do Maranhão):

\section{Fluxo de Comercialização do Babaçu}

Quebradeiras de coco Pequenos intermediários

(produtores agroextrativistas) (barraqueiro/atravessador)

Médio/grande intermediário $\longleftrightarrow$ Indústria (comerciante) (local/nacional)

Quadro 1: Fluxo de comercialização

Fonte: Mesquita (1999, p. 99)

A partir dos anos de 1950, as indústrias nacionais passam a receber incentivos para migrarem para o Maranhão, reduzindo os intermediários. Essa é a fase industrial ou extrato-indústria da cultura do babaçu. (REIS, 2008, p. 29)

Também marca esse período a realização de pesquisas e de estudos técnicos visando um diagnóstico acerca do desenvolvimento da região. Em 14 de março de 1957, pelo Decreto n. 41.150 do Governo Federal, foi criado o Grupo de Estudos do Babaçu, que teve por finalidade apresentar sugestões para o desenvolvimento de sua exploração. Esse grupo já identificava o babaçu como uma "[...] riqueza digna de toda atenção pelos poderes públicos [...]", em vista do total aproveitamento do fruto. (RÊGO; ANDRADE, 2006, p. 48)

Nessa década, o capital internacional perdeu a relevância nos projetos da região, as indústrias nacionais apropriaram-se da produção local, e a estrutura de produção continuou a operar em bases tradicionais. (AYRES JÚNIOR, 2007, p. 51) 
A produtividade na cata do babaçu oscilou para baixo. Isso pode ser explicado pelo fato de que apenas os capitalistas investidores recebiam os lucros da atividade. A exploração dos agricultores continuava a mesma, e a rentabilidade da cata não era suficiente para o sustento da família. Assim, extrair o coco continuava sendo uma atividade secundária. Pecuária, roça e cata coexistem, sendo que a cata se dava apenas no período de baixa das outras atividades.

Mesmo operando em bases tradicionais, até os anos de 1970, o babaçu foi um dos principais produtos de exportação do Estado do Maranhão, com índices de produção que oscilavam para baixo principalmente nos momentos de alta do algodão e do arroz. (CORDEIRO, 2008, p. 26)

Em segundo lugar, o sistema de compra e venda dos babaçus (da forma apresentada no quadro de fluxo de comercialização do babaçu) perpetuava (como ainda perpetua) a pobreza. (AYRES JÚNIOR, 2007, p. 34)

Revela-se, a partir desses dados, que o latifundiário e o comerciante dominavam (e dominam) a cadeia produtiva. $\mathrm{O}$ comerciante reduzia o preço pargo pela produção, desestimulando sua continuidade. Dessa forma, apesar de a capacidade produtiva da mata ser constante, a quantidade de coco recolhida oscilava em virtude de outros fatores (safra agrícola, preços, acesso às zonas de produção).

A Lei Sarney (MARANHÃO, 1969) é considerada um marco que altera as relações entre extrativistas e proprietários de terra, principalmente por conta do incentivo à pecuária no Maranhão. Essa lei revela-se continuidade ao I Plano de Governo (1968) e o Novo Zoneamento do Estado do Maranhão (1969). (RÊGO; ANDRADE, 2006, p. 48; REIS, 2008, p. 39)

A partir dos anos de 1970, tem início a segunda frente de expansão da pecuária (a primeira foi no período de 1920-1950), bem como a adoção da ideia desenvolvimentista e a intenção de construir parques industriais no Maranhão.

Essa década também é identificada com a queda da produção de amêndoas e perda do espaço do babaçu na economia local e nacional (REIS, 2008, p. 45). Reforçando essa análise tem-se a edição de Decretos 
Estaduais que permitiram que as empresas e as indústrias derrubassem milhares de hectares de babaçu. (RÊGO; ANDRADE, 2006, p. 28)

Em 1979 foi criado o Instituto Estadual do Babaçu (INEB), nele eram realizados estudos acerca do aproveitamento integral do coco, a fim de conciliar os interesses das indústrias oleaginosas, das carvoarias, dos camponeses e do governo. (RÊGO; ANDRADE, 2006, p. 28)

O pico da atividade deu-se em 1979, quando foram recolhidas e comercializadas 250.913 (duzentas e cinquenta mil, novecentos e treze toneladas/ano de amêndoas). Já na década de 1980, essa cifra não ultrapassa 100.000 (cem mil) toneladas/ano. (AYRES JÚNIOR, 2007, p. 43-44)

Com a queda do interesse pelo babaçu, os conflitos por terras são acirrados. Grilagem. Passa a ser comum a vedação de acesso aos babaçuais. As relações entre proprietários e não proprietários tornam-se cada vez mais violentas. $\mathrm{O}$ espaço doméstico necessita, então, ser organizado. Todos precisam engajar-se na luta pela sobrevivência.

Na década de 1990, é possível observar a organização do movimento das quebradeiras de coco, e, principalmente, a luta pelo controle da atividade, sem atravessadores. O processo produtivo foi transformado. Surgem novas maneiras de organização institucional e as quebradeiras associam-se para que todas possam ganhar com a exploração do babaçu.

Foram criadas as cantinas, que consistem em espaços destinados à compra de amêndoas de babaçu e à troca de mercadorias (gêneros alimentícios) diretamente nos povoados, e sua administração era realizada pelas próprias famílias camponesas. Esse sistema caracterizou-se pelo estabelecimento de redes de relações que primavam pela valorização da economia camponesa, sua subsistência e reprodução. (RÊGO; ANDRADE, 2006, p. 50-52)

Para exemplificar essa mudança no processo produtivo, serão apresentados alguns dados do Relatório Financeiro da Fábrica das Quebradeiras de Coco Babaçu - fábrica pertencente à Associação das Quebradeiras de Coco Babaçu de São José dos Basílios, MA, constituída por mulheres extrativistas e fundada em 18 de março de 2001, devidamente inscrita no CNPJ sob o número 04467420/0001-33. 
Nessa associação, o coco é recolhido em cantinas localizadas na zona rural de São José dos Basílios, Joselândia e Governador Archer, MA. O preço pago pela associação por quilo da amêndoa é $\mathrm{R} \$ 1,50$ (um real e cinquenta centavos), superior ao pago pelo atravessador, $\mathrm{R} \$ 1,00$ (um real). No Estatuto da associação lê-se a previsão de que, havendo lucros, eles devem ser investidos na própria fábrica.

O coco é beneficiado na fábrica, por meio do seguinte processo: a amêndoa é triturada em uma forrageira, depois o coco triturado é colocado em uma grande panela, onde é cozido através de uma prensa que funciona a vapor, e o combustível dessa prensa é a casca do coco que também é comprada das quebradeiras associadas. Depois de cozido o coco, ele é prensado e cerca de $47 \%$ do seu bagaço se transforma em óleo bruto. $\mathrm{O}$ restante do bagaço serve como ração animal (Entrevista por e-mail). ${ }^{3}$

Até 2010 existia apenas uma máquina para beneficiar o babaçu na fábrica. Em 2011, foi adquirida mais uma com recursos da paróquia de São José dos Basílios e, em 2012, a terceira máquina foi adquirida com recursos das próprias quebradeiras (Entrevista por e-mail).

Percebe-se, assim, que o fruto todo do babaçu é aproveitado, e com a ausência dos atravessadores o valor recebido por quilo de amêndoa, para associadas e não associadas, é superior ao oferecido pelo mercado.

É possível perceber, ainda, pelo Gráfico 1 os valores mensais em reais $(\mathrm{R} \$$ ) obtidos por cada um dos produtos (sabão, óleo, borra, ralão) no ano de 2010, pela Associação das Quebradeiras de Coco Babaçu de São José dos Basílios, MA.

3 Entrevista por e-mail com Marcos Robério dos Santos, diretor da Associação das Mulheres Quebradeiras de Coco Babaçu de São José dos Basílios. 


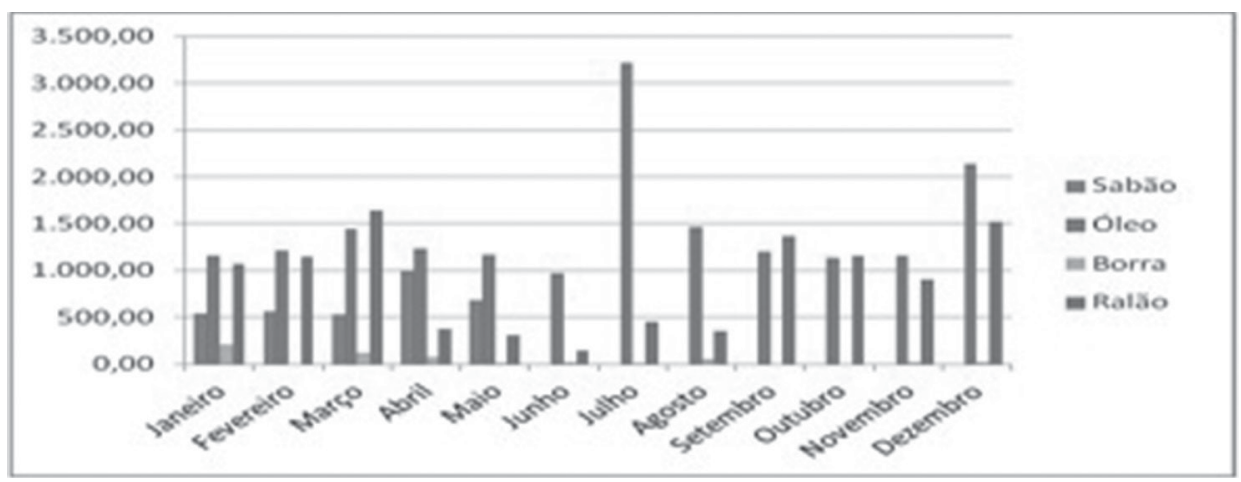

Obs.: em alguns meses ou não houve receita ou os dados não estão disponíveis.

Gráfico 1: valores mensais em reais (R\$) obtidos no ano de 2010, pela Associação das Quebradeiras de Coco Babaçu de São José dos Basílios, MA

Fonte: Marcos Robério dos Santos, diretor da Associação das Mulheres Quebradeiras de Coco Babaçu de São José dos Basílio

\begin{tabular}{|l|c|c|c|c|}
\hline \multicolumn{1}{|c|}{ Produto/Mês } & Óleo & Sabão & Ralão & Borra \\
\hline Janeiro & $1.157,70$ & 547,00 & $1.072,00$ & 211,50 \\
\hline Fevereiro & $1.211,70$ & 559,75 & $1.146,00$ & \\
\hline Março & $1.443,20$ & 531,50 & $1.644,50$ & 122,50 \\
\hline Abril & $1.232,00$ & $1.007,50$ & 377,00 & 75,00 \\
\hline Maio & $1.171,65$ & 685,50 & 308,70 & 18,00 \\
\hline Junho & 970,90 & & 149,00 & 28,00 \\
\hline Julho & $3.214,55$ & & 453,15 & 14,00 \\
\hline Agosto & $1.464,35$ & & 352,35 & 54,00 \\
\hline Setembro & $1.198,40$ & & $1.364,80$ & \\
\hline Outubro & $1.137,40$ & & $1.162,50$ & \\
\hline Novembro & $1.155,75$ & & 901,50 & 24,00 \\
\hline Dezembro & $2.139,45$ & & $1.519,00$ & 28,00 \\
\hline
\end{tabular}

Quadro 1: valores mensais em reais (R\$) obtidos no ano de 2010, pela Associação das Quebradeiras de Coco Babaçu de São José dos Basílios, MA

Fonte: Entrevista com Marcos Robério dos Santos, diretor da Associação das Mulheres Quebradeiras de Coco Babaçu de São José dos Basílio

No Gráfico 2) e na Tabela 1, é possível observar os valores referentes ao saldo em caixa da Associação das Quebradeiras de Coco Babaçu de São José dos Basílios, MA, no ano de 2010. Valores em Reais (R\$). 


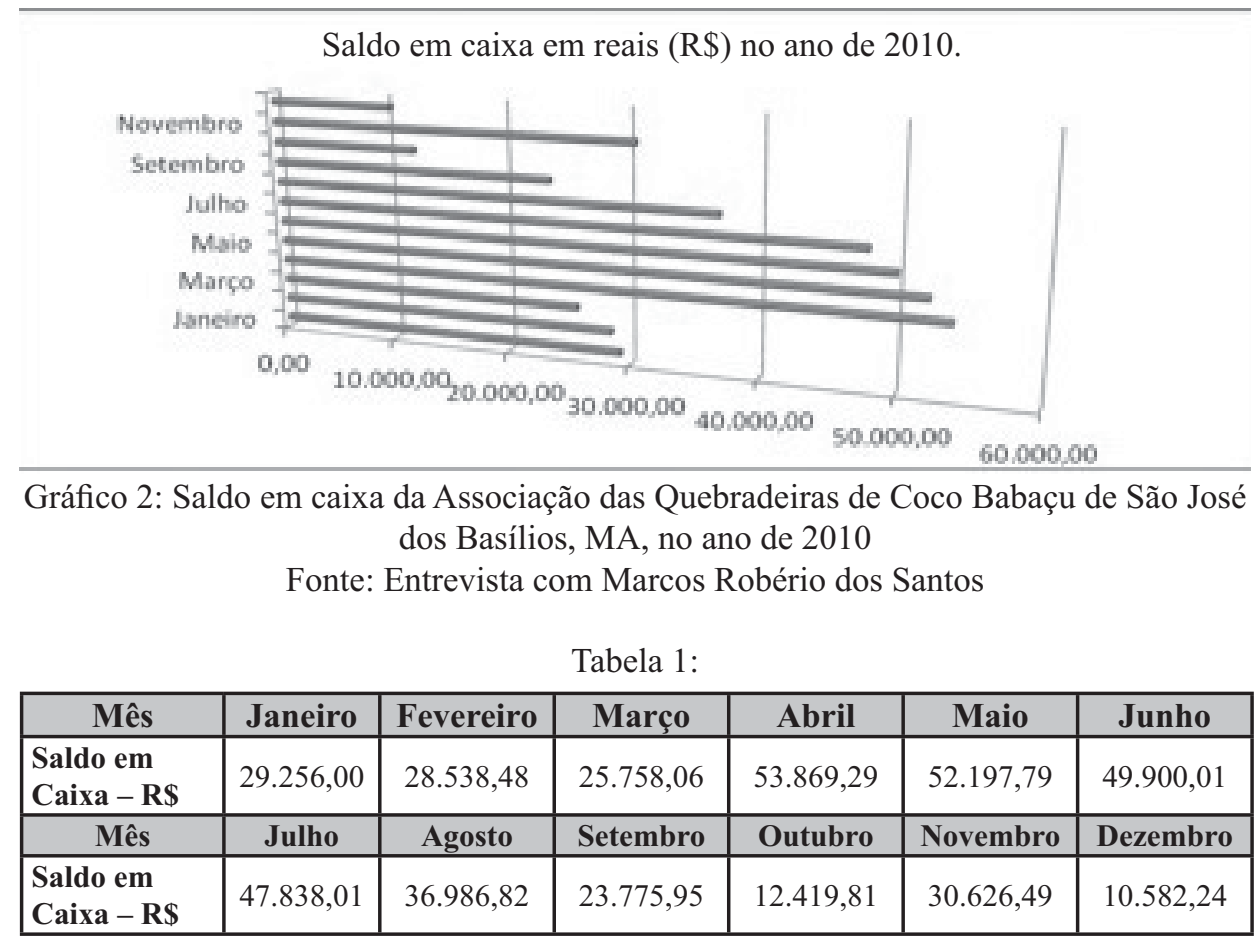

Fonte: Entrevista com Marcos Robério dos Santos

Com esse dinheiro as quebradeiras pagam despesas da cooperativa e tributos; organizam encontros; e reinvestem na fábrica (quando possível). O modelo horizontalizado de gestão, além de aumentar a autoestima, melhorar a percepção sobre a sociedade e emancipar essas mulheres, também lhes traz maiores rendimentos.

Nesse primeiro momento de análise, percebe-se a viabilidade econômica do agroextrativismo do babaçu. As mudanças no modo de produção ocorridas na década de 1990 só foram possíveis a partir do acirramento dos conflitos e da necessidade de reorganização espacial, a partir da luta para alcançar os palmeirais, que trouxe um novo paradigma de exploração do babaçu, mais horizontal e sustentável. 


\section{As Quebradeiras de Coco, o Movimento Social e a Construção de sua Identidade}

Inicialmente, é possível refletir acerca das condições em que as relações de poder, envolvendo a extração do babaçu, são percebidas no âmbito público.

Conforme delineado no item anterior, a consolidação da apropriação privada das áreas dos babaçuais teve como importante marco a Lei Sarney, que garantiu aos fazendeiros condições de acúmulo das árvores, afastando a moradia das quebradeiras de coco das áreas de acesso às palmeiras. Além disso, após essa lei, para continuarem a exercer suas atividades, elas deveriam firmar contratos com os novos proprietários das terras, que estipulavam, conforme a correlação de forças, as cláusulas mais interessantes para si próprios. As quebradeiras que se recusavam a se submeterem a esses contratos eram proibidas de entrar na área, sendo acusadas, inclusive, de furto, invasão de propriedade, dano, entre outros crimes. (SHIRAISHI NETO, 2006, p. 20)

Elas sofriam pela baixa remuneração, falsas acusações de sacrifício de animais, depredação de benfeitorias, por roubos diversos e sofriam a apropriação da produção agrícola pelo sistema usurário de crédito. (AYRES JÚNIOR, 2007, p. 100-106)

É a partir desse contexto de subordinação que nasceu a ideia da "sujeição" das quebradeiras de coco. Esse é o termo empregado para designar a prática abusiva dos fazendeiros frente às reivindicações das quebradeiras, restringindo direitos, mesmo em áreas públicas, uma vez que alguns proprietários não possuíam a escritura legítima da terra, utilizando-a como sua pela mera aparência de ser o proprietário. (ALMEIDA, 1995 , p. 23)

No auge da violência, diversas instituições nacionais começaram a se interessar pela causa, entre elas, a Comissão Maranhense de Direitos Humanos, a Comissão Pastoral da Terra, a Coordenadoria Ecumênica de Serviço, a Comissão Pastoral da Terra, a Federação dos Trabalhadores na Agricultura do Maranhão (FETAEMA) e os sindicatos rurais. 
O auxílio oferecido por essas organizações pode ser dividido em quatro frentes: 1) atendimento às necessidades imediatas (roupa, alimentação, vestuário, atendimento dos feridos); 2) interferência política nos centros locais e estaduais de poder; 3) publicização dos conflitos; 4) formação, capacitação e proteção das lideranças dos conflitos.

Nesse processo, uma nota é importante: o sindicato dos trabalhadores rurais muitas vezes se posicionou de forma contrária às lutas. (AYRES JÚNIOR, 2007, p. 104-106)

Logo em seguida, e depois concomitantemente, diversas instituições internacionais passaram a atuar: Misereor (Alemanha), Pão para o mundo (Alemanha), DFID (Inglaterra), Terres des Hommes (Suíça), War on Want (Inglaterra) e UNICEF. Em 1997, as quebradeiras receberam 80 mil dólares do UNICEF para montar uma fábrica de sabonetes no povoado de Ludovico, Município de Lago do Junco.

Segundo Renata dos Reis Cordeiro (2008, p. 56), na literatura produzida entre os anos de 1950 e 1980 sobre o babaçu, não é encontrado o termo quebradeira de coco. A construção dessa identidade aconteceu juntamente com a organização do movimento pela terra e trabalho.

Essa luta deu identidade e unidade a essas mulheres, elas encontravam nas companheiras o primeiro lugar para resistirem. Era no momento do trabalho que dividiam suas dificuldades e traçavam estratégias. Refletiam sobre as ações dos maridos que muitas vezes trabalhavam na derrubada dos palmeirais para os latifundiários. E identificavam o primeiro conflito a ser enfrentado dentro de casa: convencer seus maridos que o dinheiro ganho com as derrubadas era insuficiente e que a derrubada traria prejuízo para a subsistência do grupo. Tudo isso deve ser considerado em conjunto com a estrutura social patriarcal. (AYRES JÚNIOR, 2007, p. 107)

O clima de tensão é majorado com a formação da consciência política pelas trabalhadoras rurais. Ao se identificarem dentro de um grupo específico (de classe e gênero), as quebradeiras de coco passam a lutar contra a centralização fundiária e a acumulação incontrolável de riquezas naturais. 
A participação no conflito forneceu a elas novos espaços de atuação e direitos, outrora inerentes apenas aos homens. Foram descobrindo sua capacidade organizativa, reivindicatória, combativa e de contato com instituições e autoridades. Empoderaram-se. Essa participação gerou efeitos diretos em sua autoestima e na sua autopercepção, como mulheres e como um grupo. (AYRES JÚNIOR, 2007, p. 109-115)

Uma característica marcante na participação dessas mulheres é que elas passam a integrar diversas organizações simultaneamente. Diz-se, ainda, que se beneficiaram do suporte político e econômico da Igreja Católica, integraram sindicatos, se reuniram e fizeram pauta com representantes do Instituto Nacional de Colonização e Reforma Agrária (INCRA), do Ministério do Meio Ambiente e da Sociedade de Direitos Humanos e dessa forma foram adquirindo conhecimento sobre as leis e as questões fundiárias. Muitas delas se tornaram conhecidas nacional e internacionalmente. (AYRES JÚNIOR, 2007, p. 128)

O Movimento Interestadual das Quebradeiras de Coco Babaçu (MIQCB) é hoje forte instrumento de mobilização das quebradeiras de coco. O primeiro encontro ocorreu na cidade de São Luís, em 1991, onde se optou pela criação de movimento próprio (AYRES JÚNIOR, 2007, p. 125126). Em 1993 ocorreu o segundo encontro e foram tirados como principais objetivos a luta por babaçu livre e a reforma agrária, alternativas econômicas, sociais, políticas e ambientais para a exploração econômica dos babaçuais. Todavia, foi a partir do terceiro encontro, em 1995, que o movimento recebeu a atual denominação. $\mathrm{O}$ registro jurídico veio em 2001.

Importante ressaltar que "[...] as quebradeiras de coco babaçu são portadoras de uma identidade coletiva que as diferencia dos demais indivíduos e dos grupos sociais no interior do Estado Brasileiro" (AYRES JÚNIOR, 2007, p. 120). Essa identidade encontra-se ligada à preservação do ambiente dos babaçuais, um vínculo que ultrapassa a relação puramente material ou econômica. (RÊGO; ANDRADE, 2006, p. 55)

Outra série de argumentos para identificação das quebradeiras como grupo social foi trazida por Shiraishi $(2005$, p. 2), elas podem ser assim denominadas, pois se mobilizam de forma específica, trabalham em 
grupo e a relação que possuem com a natureza é bastante particular. As palmeiras de babaçu constituem-se em recurso vital para as quebradeiras.

\section{Identificação dos Principais Obstáculos à Continuidade e De- senvolvimento das Atividades das Quebradeiras de Coco}

Em São José dos Basílios, município maranhense distante cerca de 310 quilômetros da capital São Luís, as quebradeiras de coco babaçu se organizaram em associação e têm conquistado a segurança dos seus direitos e o livre acesso à grande parte das reservas dos babaçuais. Até pouco tempo, em uma negociação com proprietário de fazenda, ele pagava às trabalhadoras pela coleta dos cocos e estabelecia com as quebradeiras uma relação denominada no local de "pagamento de meia". Por esse sistema, as quebradeiras repassavam metade da produção ao fazendeiro. $\mathrm{O}$ litro da amêndoa custava $\mathrm{R} \$ 0,60$ para as quebradeiras e era revendido para os chamados atravessadores que, por sua vez, vendiam o produto às grandes empresas produtoras de ferrogusa ou de óleo industrial (informação verbal). ${ }^{4}$

Rosinete Silva, quebradeira de Dom Pedro, MA, afirma que ela e as companheiras eram obrigadas a passar por baixo das cercas de arame farpado, junto com seus filhos e filhas menores, muitas vezes enfrentando a "humilhação dos trabalhadores das fazendas" (informação verbal)s.

O Ministério Público em São José dos Basílios, MA, tem atuado nas demandas de preservação dos babaçuais e do livre acesso das quebradeiras de coco, na preservação dos recursos hídricos e agroextrativistas e na regularização da situação fundiária. Segundo Marcos Robério dos

\footnotetext{
4 Informação oral obtida por ocasião de conversa com Marcos Robério dos Santos, diretor da Associação das Mulheres Quebradeiras de Coco Babaçu de São José dos Basílios, na oportunidade do Encontro das quebradeiras de coco de Dom Pedro, São José dos Basílios e Governador Archer, no dia 25 de junho de 2011, em Dom Pedro, MA.

5 Informação oral obtida por ocasião de conversa com Rosinete Silva, da comunidade São Francisco Xavier, em Dom Pedro, na oportunidade do Encontro das quebradeiras de coco de Dom Pedro, São José dos Basílios e Governador Archer, no dia 25 de junho de 2011, em Dom Pedro (MA).
} 
Santos (informação verbal) ${ }^{6}$, “[...] a demanda por políticas públicas não se prende à mera coleta e quebra do babaçu, é intenção também do grupo que as relações fundiárias estabelecidas na cidade sejam regularizadas e que se protejam não apenas a palmeira, mas a vegetação e águas, o meio ambiente como um todo". Ainda, segundo o diretor, são de extrema importância tais demandas, uma vez que em épocas infrutíferas para a coleta do coco, outras formas de cultivo são utilizadas (pequenas colheitas de tomate, cheiro-verde e cebolinha, por exemplo).

O primeiro município do Maranhão que contou com uma lei do babaçu livre, em 1997, foi Lago do Junco (região central do Maranhão, na qual se encontra a região dos cocais, área mais abundante de palmeiras de babaçu).

De lá para cá, outras cidades editaram leis municipais com base no livre acesso aos babaçuais. As leis municipais estão assim distribuídas nas legislações locais do Maranhão: Lei n. 05/97 e Lei n. 01/2002 de Lago do Junco, Lei n. 32/99 de Lago dos Rodrigues, Lei n. 255/99 de Esperantinópolis, Lei n. 319/2001 de São Luiz Gonzaga, Lei n. 1.084/2003 de Imperatriz, Lei n. 466/2003 de Lima Campos, Lei n. 52/2005 de São José dos Basílios, Lei n. 01/2005 de Cidelândia, Lei n. 1.137/2005 de Pedreiras. Há projeto de lei em tramitação no município maranhense de Capinzal do Norte. (CORDEIRO, 2008, p. 93-94)

No Encontro das Quebradeiras de Coco de Dom Pedro, São José dos Basílios e Governador Archer, é possível ouvir a narrativa das quebradeiras acerca da sua experiência. Toma-se nota sobre as comunidades, a existência ou não de associações, a identificação de lideranças e os principais problemas e conquistas ao longo da luta.

Com isso, identificou-se que, em algumas cidades, as comunidades de quebradeiras de coco, ao contrário do que se pensa, não se encontram juntas e homogêneas em determinado lócus, como Dom Pedro, MA. Relatam as quebradeiras que cada comunidade tem seus problemas específi-

6 Diretor da Associação das Mulheres Quebradeiras de Coco Babaçu de São José dos Basílios. 
cos, mas que sempre encerram em um lugar comum: a falta de acesso ao extrato e ao corte do babaçu (informação verbal). ${ }^{7}$

A cidade de Dom Pedro não tem uma associação formada (como a de São José dos Basílios), e as lideranças também não são reconhecidas pelas quebradeiras, a única liderança apontada é Márcia Palhano, que faz parte da Comissão Pastoral da Terra (CPT).

Maria de Fátima Pereira narra um curioso fato:

Eu fui pegar o coco, mas meu menino tinha saído e não podia ir comigo subir no pé. Daí eu fui sozinha e nessa fazenda tinha um touro muito valente que o dono deixava solto de propósito, só para não deixar a gente entrar, porque ele sabia do medo que a gente tinha. Eu subi no pé de babaçu, mas aí o touro apareceu e eu fiquei com medo de descer porque o touro ficou lá arrodeando, me cercando por baixo. Demorei mais de meia hora pendurada lá e gritando "socorro", até que chegou alguém e tangeu o touro e eu desci. (informação verbal) ${ }^{8}$

Para as quebradeiras, a coleta do coco apenas é possível se elas entrarem furtivamente na propriedade cercada, pois não há acordo nenhum com o proprietário da terra. Quando há acordo, ele é mediado por alguém que arrenda o pedaço de terra para cuidar. $\mathrm{O}$ arrendamento é feito da seguinte maneira, de acordo com Irene Rodrigues, da comunidade Canto do Hermes: “[...] o dono real da fazenda, sítio ou quinta, 'arrenda', vende um determinado pedaço do lote para alguém e essa pessoa é que, a partir de então, é dona da terra e das palmeiras" (informação verbal) ${ }^{9}$. Quando

7 Informação oral obtida por ocasião de conversa com Maria do Socorro Ribeiro, da Comunidade Cajá, em Dom Pedro, na oportunidade do Encontro das quebradeiras de coco de Dom Pedro, São José dos Basílios e Governador Archer, no dia 25 de junho de 2011, em Dom Pedro (MA).

8 Informação oral obtida por ocasião de conversa com Maria de Fátima Pereira, da comunidade São Francisco Xavier, em Dom Pedro, na oportunidade do Encontro das quebradeiras de coco de Dom Pedro, São José dos Basílios e Governador Archer, no dia 25 de junho de 2011, em Dom Pedro, MA.

9 Informação oral obtida por ocasião de conversa com Irene Rodrigues, da comunidade Canto do Hermes, em Dom Pedro, na oportunidade do Encontro das quebradeiras de coco 
conseguem alguma espécie de contrato, o coco extraído e quebrado deve ser vendido para esse arrendatário a preço baixo.

Margarida Silva, da comunidade Cajá, na cidade de Dom Pedro, relatou que a Prefeitura chegou a propagandear um pequeno curso sobre artesanato e uso do coco babaçu, entretanto não houve qualquer convite às quebradeiras da cidade e o curso contava com apenas 15 vagas (em Dom Pedro, são, pelo menos, 100 famílias nas quais as mulheres que se identificam como quebradeiras).

Dos cursos preparados pela CPT, alguns não obtêm sucesso pelo fato de os maridos não deixarem as mulheres participarem, ou pelo fato de haver pouca expectativa de alguma conquista. Relatou-se, ainda, que a maioria das quebradeiras vive apenas da extração e da quebra do coco, “[...] mas pela dificuldade, algumas dependem do marido, e as que não têm essa ajuda acabam por ir para as casas lavar roupas ou fazer faxina nas casas de família" (informação verbal) ${ }^{10}$. Todas as que ali estavam recebiam o Bolsa Família, o que pressupõe a precariedade financeira deste grupo social.

Sobre o futuro não há esperanças, uma vez que as quebradeiras dompedrenses são extremamente preteridas nas ações do Poder Público local e por duas vezes já tentaram encaminhar projetos para a implantação da Lei do Babaçu Livre na cidade de Dom Pedro. Segundo Márcia Palhano, "[...] em uma das oportunidades um vereador simplesmente rasgou o projeto, ali na frente de todos". Ela afirma, ainda, que chegou a ser agredida por um assessor da Câmara Municipal quando protestou pelo ato praticado pelo vereador (informação verbal). ${ }^{11}$

de Dom Pedro, São José dos Basílios e Governador Archer, no dia 25 de junho de 2011, em Dom Pedro, MA.

10 Informação oral obtida por ocasião de conversa com Margarida Silva, da comunidade Cajá, em Dom Pedro, na oportunidade do Encontro das quebradeiras de coco de Dom Pedro, São José dos Basílios e Governador Archer, no dia 25 de junho de 2011, em Dom Pedro (MA).

11 Informação oral obtida por ocasião de conversa com Márcia Palhano, militante da Comissão Pastoral da Terra, na oportunidade do Encontro das quebradeiras de coco de Dom Pedro, São José dos Basílios e Governador Archer, no dia 25 de junho de 2011, em Dom Pedro (MA). 
No dia 30 de agosto de 2011, foi sancionado pelo Governo Estadual do Maranhão o Projeto de Lei n. 102/2011, de autoria do deputado Bira do Pindaré (PT), esse projeto fez valer o "dia estadual das quebradeiras de coco babaçu", fixado anualmente no dia 24 de setembro. Esse é um dia determinado como o dia simbólico de luta, posto que essa seja a data referência ao acontecimento do I Encontro de Quebradeiras de Coco no Estado do Maranhão.

Em São Luiz Gonzaga, no interior do Maranhão, ocorrem reuniões que tendem a discutir os conflitos ainda existentes. Nos dias 20, 21 e 22 de setembro de 2011, aconteceu o II Encontro Intermunicipal de Mulheres Quebradeiras de Coco Babaçu, no qual participaram a Associação de Mulheres Quebradeiras de Coco Babaçu (AMTQC), o Movimento Interestadual das Quebradeiras de Coco Babaçu (MIQCB), a Associação em Áreas de Assentamentos no Estado do Maranhão (ASSEMA), o Coletivo de Mulheres Trabalhadoras Rurais do Maranhão (CMTR), o Centro de Consciência Negra de Pedreiras e Região do Médio Mearim (CCNP) e o Sindicato dos Trabalhadores e Trabalhadoras Rurais de São Luis Gonzaga (STTR). (AMTQC, 2011, p. 1)

O tema desse encontro foi "Mulheres Quilombolas", algo que caracteriza uma nova forma de identificar as comunidades tradicionais, uma forma que se desprende de velhos rigores e historicismos e se adaptam às identidades acionadas a cada momento da vida, saindo de uma noção de tradição que está para além dessa visão temporal particular a um conjunto de fenômenos que moldam dentro de discursos que fazem questão de apagar acontecimentos e sujeitos, para moldá-los em estruturas fixas. (FOUCAULT, 2008, p. 6)

Como no esquema seguido pelo Encontrão do MIQCB, esse encontro Intermunicipal também editou carta aberta para a sociedade, com as demandas e as necessidades do município de São Luis Gonzaga do Maranhão e das regiões adjacentes, entregue à Promotoria Pública Justiça, com pequena manifestação em frente ao prédio da Promotoria. (AMTQC, 2011, p. 4) 


\section{A Necessidade de Regulamentação e Proteção Jurídica da Ati- vidade}

Apesar de certos entraves, por conta do poder público junto a interesses privados, as quebradeiras de coco babaçu conquistaram algumas leis municipais de apoio ao babaçu livre, o que não tem sido suficiente.

Assim, a ilusão do Direito, como forma igualitária de regulamentação das normas, tem dois aspectos: a primeira é a de um legislativo que cria leis; e a segunda é a de que essas leis se materializam na sociedade. (GOYARD-FABRE, 2002, p. 171)

Observa-se que a mobilização das quebradeiras tende a ultrapassar os muros das Casas e órgãos do Poder Público e também da Academia, fazendo com que sua voz chegue para além de sua comunidade, estendendo-se para que a própria sociedade perceba o conflito, problematizando-o. Entretanto, o Poder Judiciário ainda é pouco acionado.

Ressalta-se que uma base legal para o babaçu livre não se limita a colocar as novas regras para que sejam assimiladas e acatadas dentro de uma ordem já estabelecida. É preciso adicionar que a transformação de uma instituição autoritária só é possível junto com a convicção de que a ordem vigente está em crise constante e não atende mais às demandas de todos. (LUKÁCS, 2003, p. 467)

O Maranhão é o Estado que concentra a maior parte de palmeiras de babaçu do Brasil, porém essas áreas estão localizadas em propriedades privadas, cuja extração de coco não é a principal fonte de renda dos donos, que, mesmo assim, impedem a entrada das quebradeiras.

Para Shiraishi (2005, p. 6-7)

Além dos instrumentos da desapropriação pra fins de reforma agrária outros instrumentos jurídicos entram nessa discussão, como a reserva extrativista, a servidão administrativa e a própria ideia do babaçu livre. No caso da reserva extrativista, é importante salientar que não foi uma demanda oriunda do Movimento, mas foi absorvida pelas quebradeiras de coco por se tratar de um instrumento que 
poderia de certa forma atender as suas reivindicações, sobretudo daquelas mulheres que se encontram destituídas de terra.

Uma lei de abrangência nacional para regular a matéria transformou-se no Projeto n. 1.428/1996. Esse Projeto foi arquivado e desarquivado várias vezes e, atualmente, é o Projeto de Lei n. 747/2003, que se encontra arquivado na mesa diretora da Câmara dos Deputados. (BRASIL, 2012; SHIRAISHI, 2005, p. 7)

As relações em torno da extração do babaçu revelam-se agressoras de preceitos constitucionais como o valor social do trabalho (art. $1^{\circ}$, IV, CF/88), e a proteção aos conhecimentos tradicionais (art. 216, I e II, $\mathrm{CF} / 88$ ).

Reconhecendo que a atividade das quebradeiras de coco do babaçu constitui uma atividade diferenciada sob o aspecto cultural e histórico, importa saber, neste momento, se há a necessidade/obrigação por parte do Poder Público em adotar condutas voltadas a proteger essa atividade.

Salienta-se que, dentro do contexto de pluralismo jurídico, em que se reconhece a existência de uma sociedade plural, não hegemônica, em que o Estado não é a única fonte do Direito, é de se reconhecer no ambiente de populações tradicionais a existência de peculiaridades que necessitam ser observadas no momento da construção de um sistema protetivo. (SANTILI, 2004, p. 357-358)

Já fora salientado anteriormente que a legislação produzida nesses territórios pouco contribuiu para a sustentabilidade da atividade das quebradeiras. A utilização do Direito como forma de opressão não é novidade. As formas de Estado e de governo até o século XX procuravam privilegiar um determinado segmento social, em detrimento de outros. A independência das colônias permitiu uma reorganização da ordem social e econômica, mantendo-se os privilégios de pequenos grupos, geralmente grandes proprietários de terra, pois como afirmam Fagundes e Wolkmer (2011, p. 377):

Poucas vezes, na história da região, as constituições liberais e a doutrina clássica do constitucionalismo político reproduziram, rigo- 
rosamente, as necessidades de seus segmentos sociais majoritários, como as nações indígenas, as populações afro-americanas, as massas de campesinos agrários e os múltiplos movimentos urbanos.

No entanto, recente movimento constitucionalista latino-americano procura se utilizar desses instrumentos jurídicos para o atendimento das demandas das populações historicamente marginalizadas política, social e economicamente. É o que Boaventura de Souza Santos (2010, p. 80) chama de "uso contrahegemônico de instrumentos hegemônicos".

Alguns autores espanhóis citados por Fagundes e Wolkmer (2011, p. 381-384) sustentam a evolução do "neoconstitucionalismo", presente na década de 1970, e que apresenta normas materiais e substantivas que condicionam a atuação do Estado, passando pelo "novo constitucionalismo", que, mais além de uma preocupação jurídica, apresenta uma preocupação política com a legitimidade da soberania popular, chegando, finalmente, ao "novo constitucionalismo latino-americano", que busca atender às demandas vitais das comunidades que não experimentaram o Estado Social, indo além da construção de um modelo jurídico garantidor dos direitos sociais e da formulação de mecanismos de legitimação popular, sem, no entanto negar essas conquistas.

O sistema jurídico atualmente existente no Brasil permite essa utilização do Direito como mecanismo garantidor das atividades tradicionais, objeto deste estudo.

Nesse contexto, sendo um dos objetivos específicos deste estudo identificar a competência dos entes federativos na elaboração de normas protetivas sobre a presente atividade, faz-se necessário identificar "o que" se pretende tutelar. Seriam babaçuais ou seria a atividade de exploração do coco do babaçu pelas quebradeiras? Note-se que ambos devem ser tutelados, conforme artigo 24, incisos VI e VII; $215 \S 1^{\circ}$; 216 caput e incisos I e II e $\S 1^{\circ}$, artigo 225 caput e $\S 1^{\circ}$ inciso III, todos da Constituição Federal.

No entanto, por uma questão de especialização do bem jurídico tutelado, verifica-se que somente proteger os babaçuais deixaria de lado a determinação constitucional de proteção daquele conhecimento tradicio- 
nal. Assim, torna-se necessário que esse conhecimento seja tutelado em todos os seus aspectos, dentro dos quais se inclui, de maneira reflexa, a questão ambiental de proteção de determinado tipo de flora. É o que assegura e determina a Constituição Federal, em seu artigo 24, incisos VI e VII e parágrafos ao atribuir competência concorrente à União, aos Estados e ao Distrito Federal para legislar sobre proteção ao meio ambiente e ao patrimônio cultural.

Assim, a proteção da atividade das quebradeiras de coco, inserida na ideia de conhecimento tradicional, deverá ser tutelada pela União e pelos Estados, o que pressupõe a proteção do meio ambiente como requisito para a efetiva tutela do bem principal, pois não se protegendo a árvore, não haverá como exercer a atividade.

O mesmo artigo 24 da Constituição Federal estabelece que a União elabore normas gerais. Essa definição de competência deve ser interpretada em conjunto com o que estudos anteriores, inicialmente tratados na década de 1970, identificaram como "Teoria das Escalas". (KRELL, 2005, p. 182$)^{12}$

A competência concorrente verificada no caso ora em tela determina, portanto, que caberá à União tutelar a atividade como conhecimento tradicional; e aos Estados também tutelar essa atividade, mas de uma forma mais específica, uma vez que se verifica que tal atividade é peculiar àqueles espaços geográficos situados no Estado do Maranhão. Trata-se, portanto, de proteger uma forma de cultura regional.

$\mathrm{Na}$ ausência de norma protetiva estadual no exercício de suas competências próprias, poderá a União (ou até mesmo o Município, com base no artigo 30, I, II e IX, CF/88) legislar plenamente sobre a matéria. E no sentido contrário, na ausência de norma geral federal, poderá o Estado exercer sua competência suplementar (art. $24, \S \S 2^{\circ}$ e $3^{\circ}, \mathrm{CF} / 88$ ), elaborando normas gerais.

\footnotetext{
12 Andreas J. Krell informa que essa teoria foi apresentada pela cientista política Ana M. Brasileiro, do IBAM, e depois retomada por Fernando Antônio Rezende da Silva, na obra "Repartição de encargos públicos na Federação Brasileira". Ver em: CEPAM/FUNDAP A nova Constituição Paulista: São Paulo, Perspectivas, 1989, p. 19-44.
} 
Sob outro aspecto, somente uma análise mais detalhada das peculiaridades da extração do coco babaçu poderá determinar o modo e o tempo de intervenção pública destinada a sua tutela. Existem diversos mecanismos legais voltados para esse mister, conforme mencionado por Sandra Akemi Shimada Kishi (2010, p. 194-207), iniciando-se pela própria Constituição Federal e passando pela Convenção da Diversidade Biológica, (incorporada ao nosso ordenamento jurídico com sua ratificação pelo Congresso Nacional em 03/02/1992, pelo Decreto Legislativo n. 2), a Medida Provisória n. 2.186/2001, o Decreto n. 6.040/2007, dentre outros diplomas legais, não se olvidando ainda da possibilidade de aplicação da Lei n. 9.985/2000, que dispõe sobre o Sistema Nacional de Unidades de Conservação da Natureza (SNUC), que, dentre seus objetivos, determina a proteção dos "[...] recursos naturais necessários à subsistência de populações tradicionais, respeitando e valorizando seu conhecimento e sua cultura e promovendo-as social e economicamente". (BRASIL, 2000, art. $\left.4^{\mathrm{o}}, \mathrm{XII}\right)$

A alternativa possível é a criação de uma lei de abrangência nacional que desvincule a propriedade da terra da propriedade do babaçu nela encontrado, cedendo livre acesso para os que dele dependam como alternativa direta de sobrevivência. Todavia, nessa hipótese, estar-se-ia diante de competência privativa da União (art. 22, I da CF), que, pela falta de norma complementar (art. 22, parágrafo único da $\mathrm{CF}$ ), não pode ser delegada para os Estados.

Dessa forma, pode-se entender que existe uma competência estadual para a edição da Lei do babaçu livre, e que, na ausência do exercício dessa competência, a União ou o Município poderão legislar sobre a matéria. Além disso, outros mecanismos jurídicos, já em vigor, são passíveis de utilização, conforme o interesse a ser tutelado - seja a atividade e conhecimento tradicional, seja a subsistência das famílias, ou o acesso aos babaçuais. 


\section{Conclusão}

A partir da pesquisa feita, revelou-se um grande potencial econômico do babaçu, e mais do que isso, a possibilidade de empoderamento financeiro das próprias populações tradicionais, que manejam a terra de forma sustentável e distribuem a riqueza gerada no processo.

Percebeu-se, também, que as mulheres quebradeiras de coco passam por diferentes conflitos, que não se limitam apenas ao acesso aos babaçuais, havendo conflitos de gênero, de classe, bem como questões deficitárias no que tange à sua educação, qualidade de vida e outros aspectos que ferem a proteção à dignidade prevista da na Constituição Federal.

Ademais, restou verificada a relação entre a dificuldade na edição e na efetivação das leis do babaçu livre e a propriedade da terra, principalmente os interesses privados de membros do legislativo dos locais dos conflitos.

O novo constitucionalismo latino-americano, no entanto, aponta a possibilidade de utilização dos instrumentos do Direito para o atendimento das diversas demandas sociais.

A mobilização das quebradeiras, em suma, não se reduz à mera reivindicação por publicações legislativas. Existem demandas por melhoria das condições de vida e de trabalho, respeito por sua atividade, proteção e preservação do meio ambiente e reconhecimento da sua atuação.

Os ingressos na Assembleia Legislativa, Promotorias, Órgãos do Executivo, para a entrega de cartas de reivindicação e propostas de melhoria das condições, mostra que a mobilização desse grupo tende a crescer e, com isso, aumentar a visibilidade de seus conflitos e suas demandas.

A sociedade está intimamente ligada à situação de lutas na medida em que o êxodo, provocado pela proibição e restrição da coleta do coco, aumenta e inflaciona os índices populacionais dos espaços identificados como urbanos, aumentando o número de pessoas abaixo da linha de pobreza e que estejam envolvidas em conflitos sociais.

A partir da análise das qualidades do babaçu, fruto que pode ser integralmente utilizado na indústria e, que, atualmente, tem como valor 
agregado o fato de ser produto "verde", provindo de produção "tradicional" na Amazônia, bem como da atividade extrativista organizada a partir de associações e cooperativas de quebradeiras de coco, constatou-se a possibilidade da extração do babaçu como ferramenta econômica de emancipação local e de fortalecimento de uma economia horizontalizada, que empodera pessoas, respeita o meio ambiente e produz valor econômico.

Com os instrumentos jurídicos corretos, a atividade extrativista estudada pode ser normatizada e protegida, aumentando o interesse por essa atividade nestes três níveis: social, econômico e proteção ao meio ambiente.

Outra economia é possível. Outro mundo também!

\section{Referências}

ALMEIDA, Alfredo Wagner Berno de. Quebradeiras de coco: identidade e mobilização. São Luís: MIQCB, 1995.

AMARAL FILHO, Jair do. A economia política do babaçu: um estudo da organização da extrato-indústria do babaçu no Maranhão e suas tendências. São Luís: SIOGE, 1980.

ANDRADE, Manuel Correia de. Nordeste, espaço e tempo. Petrópolis: Vozes, 1970.

AMTQC. Carta aberta das Quebradeiras de coco babaçu. In: III ENCONTRO INTERMUNICIPAL DE MULHERES QUEBRADEIRAS DE COCO BABAÇU. São Luís Gonzaga, MA. 2011. Anais... São Luís Gonzaga, 2011. Disponível em: <http://www.g1 sucesso.com.br/carta aberta_57.html>.Acesso em: 29 set. 2011.

ASSEMBLEIA Legislativa do Maranhão (ALMA). Quebradeiras de coco entregam dois projetos ao deputado Bira do Pindaré, 26 de maio de 2011. Disponível em: <http://www.al.ma.gov.br/novo/noticias. php?codigo1=19602>. Acesso em: 29 set. 2011. 
AYRES JUNIOR, José Costa. A Organização das Quebradeiras de Coco Babaçu e a Refuncionalização de um Espaço Regional na Microrregião do Médio Mearim Maranhense. Dissertação apresentada no programa de mestrado do curso de Geografia do Centro de Filosofia e Ciências Humanas da UFSC. 2007.

BRASIL. Câmara Dos Deputados. Ficha de tramitação Projeto de Lei n. 747/2003. Disponível em: <http:/www.camara.gov.br/ proposicoesWeb/fichadetramitacao?idProposicao=111327>. Acesso em: 5 dez. 2012.

CORDEIRO, Renata dos Reis. Velhos conflitos em novas causas: um estudo sobre processos de ambientalização dos discursos do Movimento Interestadual das Quebradeiras de Coco Babaçu no Maranhão. 114f. Dissertação apresentada no programa de mestrado da UFMA. Centro de Ciências Humanas, sob orientação de Horário Antunes de Sant'ana Júnior. 2008.

FAGUNDES, Lucas Machado; WOLKMER, Antonio Carlos. Tendências contemporâneas do constitucionalismo latino-americano: estado

plurinacional e pluralismo jurídico. Pensar, Fortaleza, v. 16, n. 2, p. 371408, jul.-dez. 2011.

FOUCAULT, Michel. A arqueologia do saber. Rio de Janeiro: Forense Universitária, 2008.

GOYARD-FABRE, Simone. Os fundamentos da ordem jurídica. São Paulo: Martins Fontes, 2002.

IRENE Rodrigues, da comunidade Canto do Hermes, em Dom Pedro, na oportunidade do Encontro das quebradeiras de coco de Dom Pedro, São José dos Basílios e Governador Archer, no dia 25 de junho de 2011, em Dom Pedro, MA.

KISHI, Sandra Akemi Shimada. "Conhecimento tradicional, consentimento prévio fundamentado e a efetividade do acesso à biodiversidade". In: MARQUES, Claudia Lima; MEDAUAR, Odete; SILVA, Solange Teles da. O novo direito administrativo, ambiental e urbanístico: estudos em homenagem à Jacqueline Morand-Deviller. São Paulo: Revista dos Tribunais, 2010. 
KRELL, Andreas J. Autonomia municipal e proteção ambiental: critérios para definição das competências legislativas e das políticas locais. In KRELL, Andreas J. (Org.). A aplicação do direito ambiental no Estado Federativo. Rio de Janeiro: Lumen Juris, 2005.

LUKÁCS, Gyorgy. História e consciência de classe: estudos sobre a dialética marxista. São Paulo: Martins Fontes, 2003.

MACHADO, Paulo Affonso Leme. Direito ambiental brasileiro. São Paulo: Malheiros, 2003.

MARANHÃO. Lei Estadual n. 2.979, de 17 de julho de 1969.

MÁRCIA Palhano, militante da Comissão Pastoral da Terra, na oportunidade do Encontro das quebradeiras de coco de Dom Pedro, São José dos Basílios e Governador Archer, no dia 25 de junho de 2011, em Dom Pedro, MA.

MARCOS Robério dos Santos, diretor da Associação das Mulheres Quebradeiras de Coco Babaçu de São José dos Basílios, Informação oral obtida por ocasião do Encontro das quebradeiras de coco de Dom Pedro, São José dos Basílios e Governador Archer, no dia 25 de junho de 2011, em Dom Pedro, MA.

MARGARIDA Silva, da comunidade Cajá, em Dom Pedro, na oportunidade do Encontro das quebradeiras de coco de Dom Pedro, São José dos Basílios e Governador Archer, no dia 25 de junho de 2011, em Dom Pedro, MA.

MARIA DE FÁTIMA Pereira, da comunidade Canto do Hermes, em Dom Pedro. Informação oral obtida por ocasião do Encontro das quebradeiras de coco de Dom Pedro, São José dos Basílios e Governador Archer, no dia 25 de junho de 2011, em Dom Pedro, MA.

MARIA DO SOCORRO Ribeiro, da Comunidade Cajá, em Dom Pedro. Informação oral obtida por ocasião do Encontro das quebradeiras de coco de Dom Pedro, São José dos Basílios e Governador Archer, no dia 25 de junho de 2011, em Dom Pedro, MA. 
MARIA LUCINALVA Sousa, da Comunidade Centro dos Estevinhos, em Dom Pedro, na oportunidade do Encontro das quebradeiras de coco de Dom Pedro, São José dos Basílios e Governador Archer, no dia 25 de junho de 2011, em Dom Pedro, MA.

MESQUITA, Benjamin Alvino de. As relações de produção e o extrativismo do babaçu nos estado do MA, PI, PA e TO. In: A economia do babaçu: Levantamento preliminar de dados. São Luís, MA, Balaios Typographia, 1999.

MIQCB. Carta das Quebradeiras de Coco Babaçu. VI Encontro do Movimento Interestadual das Quebradeiras de Coco Babaçu. São Luís, 2009. Disponível em: <http://www.actionaid.org.br/Portals/0/Docs/ Carta_Final_VIEncontrao.doc $>$. Acesso em: 29 set. 2011.

NETTO, Luiz Lôbo. Constitucionalização do direito civil. Revista de Informação Legislativa. Brasília, DF, v. 36, n. 141, jan.-mar, p. 99-109, 1999.

PACHUKANIS, E. A teoria geral do direito e o marxismo. Coimbra: Centelah, 1977.

REIS, Renata Cordeiro. Velhos conflitos em novas causas: um estudo sobre processos de ambientalização nos discursos do Movimento Interestadual das Quebradeiras de Coco Babaçu no Maranhão 114f. Dissertação de Mestrado defendida na Universidade Federal do Maranhão. Centro de Estudos de Ciências Humanas sob orientação de Horácio Antunes de Sant'ana Júnior.

RÊGO, Josoaldo Lima; ANDRADE, Maristela de Paula. História de Mulheres: breve comentário sobre o território e a identidade das quebradeiras de coco babaçu no Maranhão. Agrária. São Paulo, n. 3. p. 47-57, 2006.

ROSINETE Silva, da comunidade São Francisco Xavier, em Dom Pedro. Informação oral obtida por ocasião do Encontro das quebradeiras de coco de Dom Pedro, São José dos Basílios e Governador Archer, no dia 25 de junho de 2011, em Dom Pedro, MA. 
SANTILI, Juliana. Conhecimentos tradicionais associados à biodiversidade: elementos para a construção de um regime jurídico sui generis de proteção. In: PLATIAU, Ana Paula Barros; VARELLA, Marcelo Dias. (Org.). Diversidade biológica e conhecimentos tradicionais. Belo Horizonte: Del Rey, 2004.

SANTOS, Boaventura de Sousa. Refundación del Estado en América Latina: perspectivas desde una epistemología del Sur. Lima: Instituto Internacional de Derecho y Sociedad, 2010.

SHIRAISHI NETO, Joaquim. Leis do babaçu livre: práticas jurídicas das quebradeiras de coco babaçu e normas correlativas. Manaus: UEA, 2006.

. Crise nos padrões jurídicos tradicionais: o direito em face dos grupos sociais portadores de identidade coletiva. Trabalho apresentado no XIV CONGRESSO NACIONAL DO CONSELHO NACIONAL DE PESQUISA E PÓS-GRADUAÇÃO EM DIREITO, realizado no período de 3-5 de novembro de 2005, em Fortaleza. Anais... Fortaleza, 2005.

SILVA, Fernando Antônio Rezende da. Repartição de encargos públicos na Federação Brasileira. In: CEPAM/FUNDAP. A Nova Constituição Paulista. São Paulo: Perspectivas, 1989. 
Miguel Etinger de Araújo Junior é Doutor em Direito da Cidade pela Universidade do Estado do Rio de Janeiro. Docente do curso de Mestrado e da Graduação em Direito na Universidade Estadual de Londrina (Londrina). E-mail: miguel.etinger@gmail.com.

Endereço profissional: Departamento de Direito Público da UEL. Rodovia Celso Garcia Cid, PR-445, Km 380, Campus Universitário. CEP 86.057-970, Londrina, PR.

Erika Juliana Dmitruk é Mestre em Filosofia e Teoria do Direito pela Universidade Federal de Santa Catarina. Docente do curso de Direito na Universidade Estadual de Londrina (Londrina).E-mail: ejdmitruk@hotmail.com. Endereço profissional: Departamento de Direito Público da UEL. Rodovia Celso Garcia Cid, PR-445, Km 380, Campus Universitário. CEP 86.057-970, Londrina, PR.

João Carlos da Cunha Moura é Mestrando Direito e Instituições do Sistema de Justiça da Universidade Federal do Maranhão.E-mail: jc_yupe@hotmail.com. Endereço profissional: UFM. Av. dos Portugueses, 1966, Baganga - CEP 65080805, São Luís, MA. 